\title{
Influences of Alternating Magnetic Fieldson the Growth Behavior and Distribution of the Primary Fe Phasein Cu-14Fe Alloys during the Solidification Process
}

\author{
Jin Zou ${ }^{1, *}$, De-Ping Lu ${ }^{1}$, Ke-Ming Liu ${ }^{2}$, Qing-Feng Fu ${ }^{1}$ and Zhe Zhou ${ }^{1}$ \\ 1 Jiangxi Key Laboratory for Advanced Copper and Tungsten Materials, Jiangxi Academy of Sciences, \\ Nanchang 330029, China; ludeping61@163.com (D.-P.L.); fuqingfeng@jxas.ac.cn (Q.-F.F.); \\ zhouzhe@jxas.ac.cn (Z.Z.) \\ 2 Jiangxi Key Laboratory for Precision Drive and Control, Nanchang Institute of Technology, \\ Nanchang 330099, China; jokeyliu@sina.com \\ * Correspondence: zoujin@jxas.ac.cn; Tel.: +86-791-8817-6529; Fax: +86-791-8817-6237
}

Received: 25 June 2018; Accepted: 23 July 2018; Published: 25 July 2018

\begin{abstract}
An alternating magnetic field (AMF) was applied during the solidification process of the $\mathrm{Cu}-14 \mathrm{Fe}$ alloy and the effect of the electromagnetic parameter, which impact the model and solidification technique of the solidification structure that were analyzed. Results show that an AMF applied during the solidification process significantly reduced macro-segregation and gas hole defects. During the growth process of the primary Fe phase, the AMF impacted the nucleation of detached grains and fusing dendrites. Specifically, the developed Fe dendrites were transformed to rosettes or spherical grains in the presence of an applied AMF while the grain distribution was more disperse and uniform. It was found that the growth behavior of Fe grains under AMF depended upon the combined effects of the electromagnetic force and electromagnetic heat.
\end{abstract}

Keywords: $\mathrm{Cu}-\mathrm{Fe}$ alloy; alternating magnetic field; solidification structure; primary Fe phase; grain growth

\section{Introduction}

Since high-strength and high-conductivity $\mathrm{Cu}$-based deformation-processed in composites were first discovered by Bevk et al. [1]. Cu-M alloys have been the subjects of considerable studies where $\mathrm{M}$ indicates body-centered cubic (BCC) crystal transition metals [2] such as $\mathrm{Cr}$ [3-5], $\mathrm{Fe}$ [6-8], $\mathrm{Nb}$ [9-11], and Mo [12,13] as well as face-centered cubic (FCC) crystal metals such as Ag [14,15]. The Cu-Fe alloy has attracted the attention of researchers because of the effective strengthening and industrial application. In the $\mathrm{Cu}-\mathrm{Fe}$ alloy, the primary Fe phase under conventional solidification is mainly a dendritic structure. Furthermore, the dendritic arm develops and tends to aggregate to form component segregation, which significantly reduces the mechanical performance of the composites. One of the key issues in the research of $\mathrm{Cu}$-Fe composites is improvement of the morphology and distribution of the primary Fe phase. Several studies have reported a refined Fe grain size with the addition of micro-alloying elements such as $\mathrm{Cr}$ [16], Ni [17], Si [18], Co [19], and Ag [20]. This multi-alloying method can improve the strength of the composites. However, the conductivity is negatively correlated with the strength where an increase in strength will induce a decrease in conductivity for most alloying elements. Furthermore, the addition of alloying elements will increase the impurity content in the $\mathrm{Cu}$ matrix, which is not conducive for the improvement of the conductivity. 
The application of an electromagnetic field during the solidification process can affect the heat and solute transport in the melt, which significantly improves the solidification structure and material performance. In particular, an AMF can effectively refine the grain size during the solidification process of an $\mathrm{Al}$ alloy where grain refinement is more significant with increased magnetic flux density [21,22]. Steinbach et al. [23] have reported that an AMF can improve the Al-Si-Mg alloy microstructure while Vives $[24,25]$ found that the AMF solidification technique promotes fine equiaxed grains in $\mathrm{Al}$ alloys. Lastly, Chen et al. [26] found that the morphology of the eutectic phase in the Pb-Sn alloy transformed from a developed dendrite to a refined equiaxed grain under AMF. Furthermore, the application of AMF during the solidification process can also purify the melt and reduce macro-segregation and casting defects in the material [27-31].

Based on these previous reports showing the significant improvement AMF can have on the solidification structure, this study investigated the influence of AMF on the primary Fe phase of the $\mathrm{Cu}-14 \mathrm{Fe}$ alloy. The aims of this work focused on the growth and distribution of the primary Fe phase in the $\mathrm{Cu}-14 \mathrm{Fe}$ alloy solidified with AMF and explored the influence mechanism of the AMF on the primary Fe phase growth and distribution.

\section{Materials and Methods}

Electrolytic copper (99.96 wt. \%) and pure iron (99.94 wt. \%) were used to prepare the Cu-14 wt. $\%$ Fe alloy. The alloys were melted in a magnesia crucible with a medium frequency induction furnace and then were solidified in a graphite crystallizer (diameter $\Phi 112 \mathrm{~mm}$ ) installed in a magnetic field generating system. The temperature of melt was measured in real-time using an infrared thermometer (IRP20, OPTRIS, Berlin, Germany). Figure 1 shows the magnetic field generating system possessing a magnetic flux density range of $0-60 \mathrm{mT}$, which were measured using a digital Gauss meter (Model: HT201, Hengtong magnetoelectricity CO.LTD, Shanghai, China). Prior to introducing the alloy, the graphite crystallizer (Dashiqiao Crucible Factory, Yingkou, China) was preheated to $600{ }^{\circ} \mathrm{C}$ for casting. The melting temperature was collected by thermocouples and acquired in real-time during the solidification process. This study investigated the effects that the electromagnetic parameters, the stirring models, and the solidification techniques had upon the solidification structure.

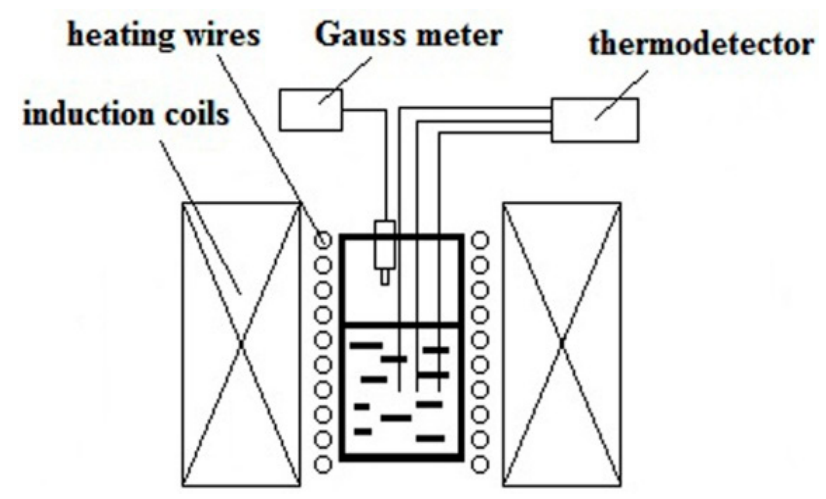

Figure 1. Schematic view of the magnetic field generating system.

Table 1 lists the experimental parameters of the magnetic field and Table 2 lists the parameters of the solidification technique. The thermodynamic parameters of the $\mathrm{Cu}-14 \mathrm{Fe}$ alloy were simulated by ProCAST software (2011.0, ESI Group, Paris, France). The magnetic field-generating device was set to possess various stirring models, which included the continuous stirring model with a constant magnetic stirring direction and the alternating stirring model exhibiting a stirring cycle of rotate $\rightarrow$ stop $\rightarrow$ reverse $\rightarrow$ stop where the stirring duration for each step in the cycle $10 \mathrm{~s}$ for a rotate and reverse step and $2 \mathrm{~s}$ for each stop step. 
Table 1. Parameters of Cu-Fe alloys solidified with AMF.

\begin{tabular}{ccccc}
\hline Alloy & $\begin{array}{c}\text { Melting Temperature } \\
\left({ }^{\circ} \mathbf{C}\right)\end{array}$ & $\begin{array}{c}\text { Pouring Temperature } \\
\left({ }^{\circ} \mathbf{C}\right)\end{array}$ & $\begin{array}{c}\text { Field Frequency } \\
(\mathbf{H z})\end{array}$ & $\begin{array}{c}\text { Magnetic Flux Density } \\
(\mathbf{m T})\end{array}$ \\
\hline & & & & 20 \\
$\mathrm{Cu}-14 \mathrm{Fe}$ & \multirow{3}{*}{1460} & 1400 & 26 & 25 \\
& & & & 33 \\
\hline
\end{tabular}

Table 2. Parameters of $\mathrm{Cu}-\mathrm{Fe}$ alloys solidification technique.

\begin{tabular}{ccccc}
\hline Alloy & $\begin{array}{c}\text { Pouring Temperature } \\
\left({ }^{\circ} \mathbf{C}\right)\end{array}$ & $\begin{array}{c}\text { Field Frequency } \\
(\mathbf{H z})\end{array}$ & $\begin{array}{c}\text { Magnetic Flux Density } \\
(\mathbf{m T})\end{array}$ & $\begin{array}{c}\text { AMF Operating Temperature } \\
\left({ }^{\circ} \mathbf{C}\right)\end{array}$ \\
\hline \multirow{2}{*}{$\mathrm{Cu}-14 \mathrm{Fe}$} & \multirow{2}{*}{1400} & 26 & & I: 1400 \\
& & & 20 & II: 1360 \\
& & & & III: 1260 \\
\hline
\end{tabular}

The ingots were initially cut longitudinally along the diameter and the smaller-sized samples were prepared by a wire-electrode cutting to $10 \times 10 \mathrm{~mm}^{2}$. Figure 2 shows the sampling positions in the ingot for the test. The samples for investigating the microstructure were polished and etched using a solution of $\mathrm{FeCl}_{3}: \mathrm{HCl}: \mathrm{H}_{2} \mathrm{O}=1: 2: 20$ and were subsequently observed with an optical microscope (OM; DMI3000M, Leica Microsystems, Wetzlar, Germany)and a transmission election microscope (TEM; JEM-2100, JEOL, Tokyo, Japan).The phase structure was determined with X-ray diffraction (XRD; D8-Advance, Bruker, Madison, WI, USA) using a tube voltage of $40 \mathrm{kV}$ and a $\mathrm{Cu} \mathrm{K}_{\alpha}$ wavelength of $1.5418 \AA$. The average Fe grain size was measured from the optical microscope images using Image-Pro Plus software(6.0, Media Cybernetics, Rockville, MD, USA).

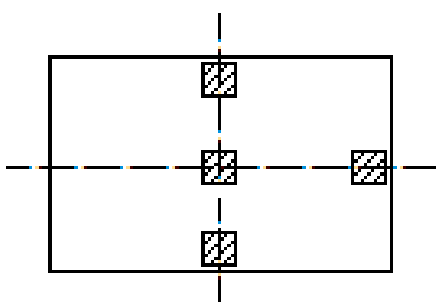

Figure 2. The sample position in the ingot.

\section{Results}

\subsection{Microstructure}

Figure 3 presents the microstructure of $\mathrm{Cu}-14 \mathrm{Fe}$ alloys solidified with and without AMF. The typical microstructures of the $\mathrm{Cu}-\mathrm{Fe}$ alloys without AMF are a primary Fe phase distributed in the $\mathrm{Cu}$ matrix with random orientations, which is shown in Figure 3a. With the application of AMF, however, the number of developed Fe dendrites and irregularly-shaped grains is reduced and the morphology of the primary Fe phase transforms from dendritic structures to rosettes or spherical grains while Fe phases are further refined and more uniformly distributed $(20 \mathrm{mT})$, which is shown in Figure $3 b$.With the increase in the magnetic flux density, the secondary dendritic arms of Fe dendrites are shortened and transformed into spherical grains $(25 \mathrm{mT})$, which is shown in Figure 3c. Figure 4 plots the average Fe grain size as a function of magnetic flux density where the grain size of the primary Fe phase exhibits significant refinement under AMF and decreases with the magnetic flux density. With the magnetic flux density of $25 \mathrm{mT}$, the average Fe grain size of $11.5 \mu \mathrm{m}$ represents a decrease of about $25 \%$ from that of a grain solidified without AMF. However, the grain size exhibits a certain amount of coarsening when the magnetic flux density exceeds $33 \mathrm{mT}$, which is shown in Figure $3 \mathrm{~d}$,e. 


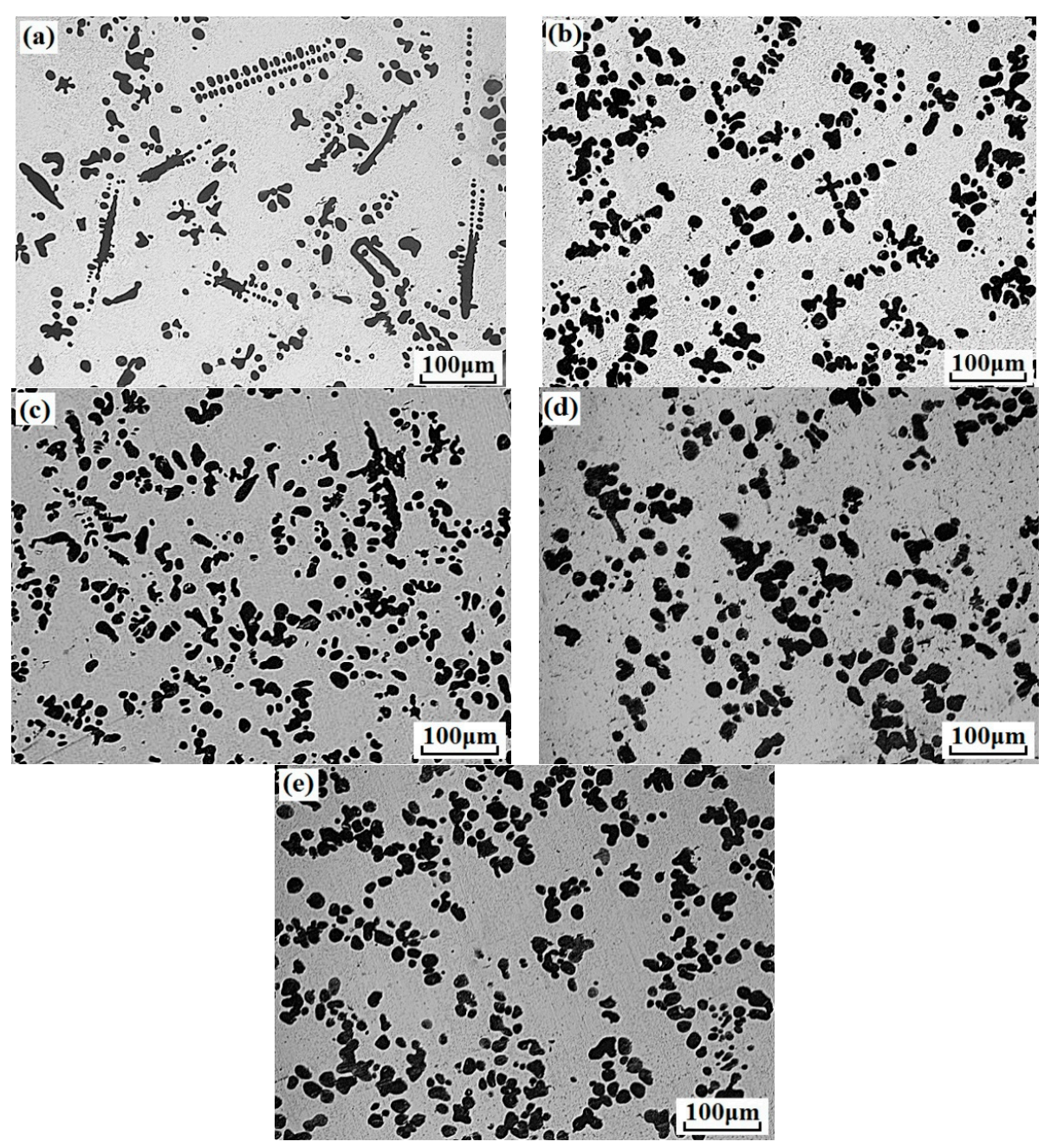

Figure 3. Microstructures of $\mathrm{Cu}-14 \mathrm{Fe}$ alloys solidified with and without AMF. (a) Without AMF, (b-e) With AMF (magnetic flux density, $B=20 \mathrm{mT}, 25 \mathrm{mT}, 33 \mathrm{mT}$, and $40 \mathrm{mT}$ ).

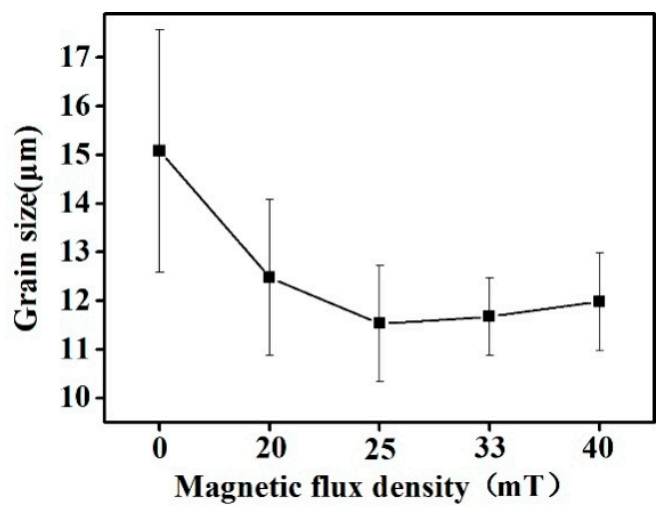

Figure 4. The average Fe grain size with various magnetic flux densities.

Figure 5 shows the phase structures of $\mathrm{Cu}-14 \mathrm{Fe}$ alloys solidified with and without AMF. In both cases, the alloys are composed of $\mathrm{Cu}$ and $\alpha$-Fe. Figure 6 shows the TEM image of $\mathrm{Cu}-14 \mathrm{Fe}$ alloys (a) and selected are a diffraction (SAED) patterns (Figure 6b,c). According to the result of SAED, the phase structures of the primary Fe phase and $\mathrm{Cu}$ matrix are b.c.c. (body-centered cubic) and f.c.c. (face-centered cubic), respectively. 


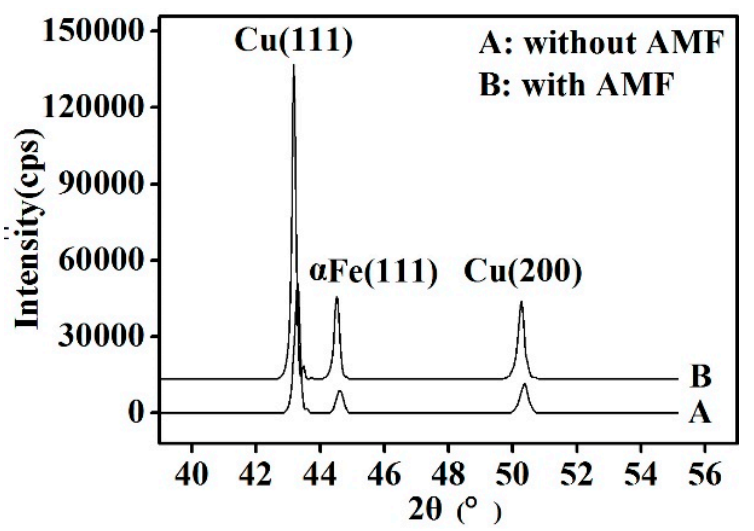

Figure 5. XRD patterns of Cu-14Fe composites.

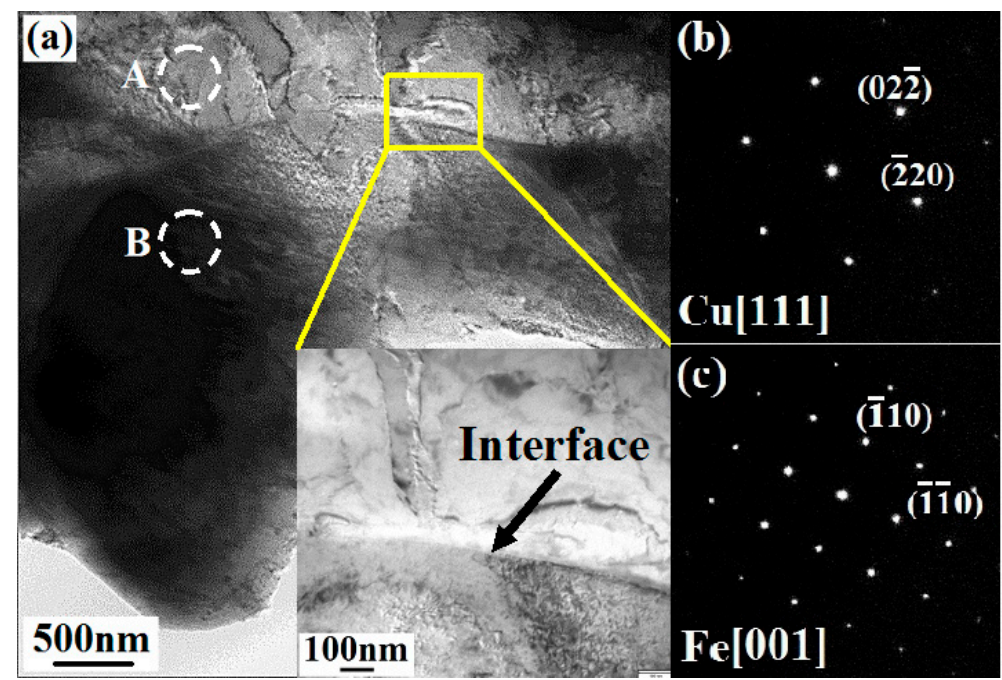

Figure 6. (a) TEM images and selected area electron diffraction (SAED) patterns of (b) Cu matrix and (c) primary Fe phase.

\subsection{Macrosegregation}

Figure 7 shows the solidification structure at the top and bottom of $\mathrm{Cu}-14 \mathrm{Fe}$ ingots solidified with and without AMF $(20 \mathrm{mT})$. As shown in Figure 3, the typical solidification structure of the Cu-14Fe alloy is a uniform distribution of the primary Fe phase in the $\mathrm{Cu}$ matrix. Figure 7a,c present the microstructure at the top and bottom, respectively, of a $\mathrm{Cu}-14 \mathrm{Fe}$ ingot solidified without AMF where it can be seen that obvious macro-segregation occurs in the ingot. The Fe dendrites are distributed unevenly. The Fe phase is almost nonexistent at the bottom of the ingots, which is shown in Figure 7c while the volume fraction of the Fe phase is relatively higher at the top. The ingot top simultaneously exhibits serious hole defects, which is shown in Figure 7a. The holes present a round shape with smooth unoxidized boundaries typical of gas holes. Figure $7 \mathrm{~b}, \mathrm{~d}$ show the microstructure at the top and bottom, respectively, of a $\mathrm{Cu}-14 \mathrm{Fe}$ ingot solidified with AMF where the primary Fe phase exhibits a more even distribution in the $\mathrm{Cu}$ matrix at the bottom, which is shown in Figure $7 \mathrm{~d}$. No hole defects are visible at the top, which is shown in Figure $7 \mathrm{~b}$. Therefore, the application of AMF during the solidification process of $\mathrm{Cu}-14 \mathrm{Fe}$ alloys can significantly reduce macro-segregation and hole defects. 

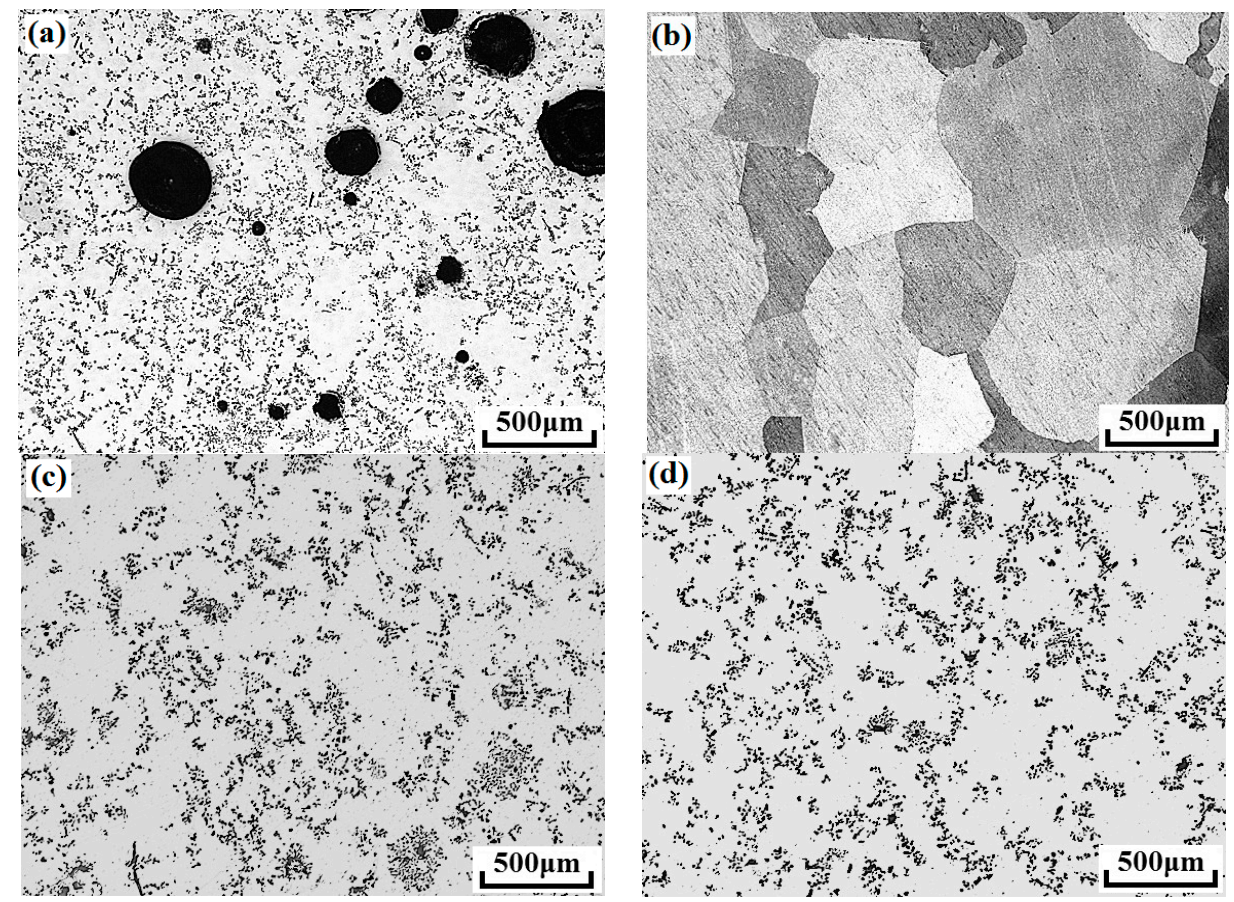

Figure 7. Solidification structure of $\mathrm{Cu}-14 \mathrm{Fe}$ alloys, without AMF: (a) top, (b) bottom; with AMF: (c) top, (d) bottom.

Figure 8 presents the solidification structure of $\mathrm{Cu}-14 \mathrm{Fe}$ alloys solidified under AMF $(20 \mathrm{mT})$ featuring two different stirring models. Figure $8 \mathrm{a}, \mathrm{b}$ show the microstructure at the edge and center, respectively, of the ingot solidified with continuous stirring. It can be seen that the distribution of the Fe phase at the ingot center is more non-uniform than that at the edge, which is shown in Figure 8a. The Fe grains at the center have a tendency to aggregate, which is shown in Figure $8 b$. Figure $8 c, d$ show the microstructure at the edge and center, respectively, of the ingot solidified with alternating stirring where it can be seen that the distribution of the Fe phase in the $\mathrm{Cu}$ matrix is more uniform and disperses at the edge, which is shown in Figure 8c, and at the center, which is shown in Figure 8d, when compared to that solidified with continuous stirring.
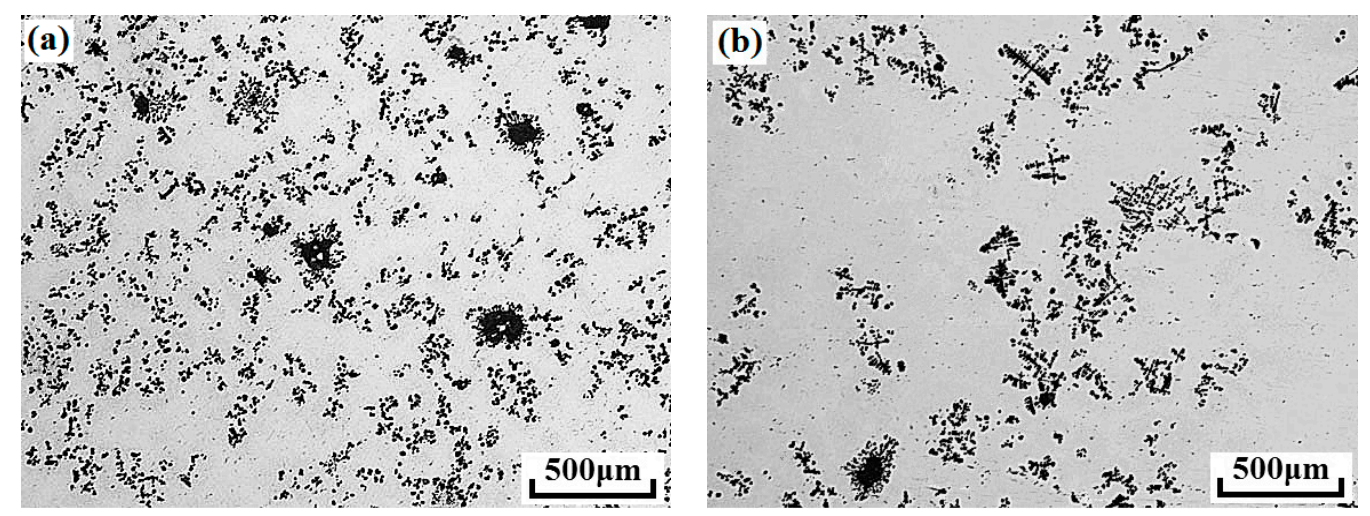

Figure 8. Cont. 

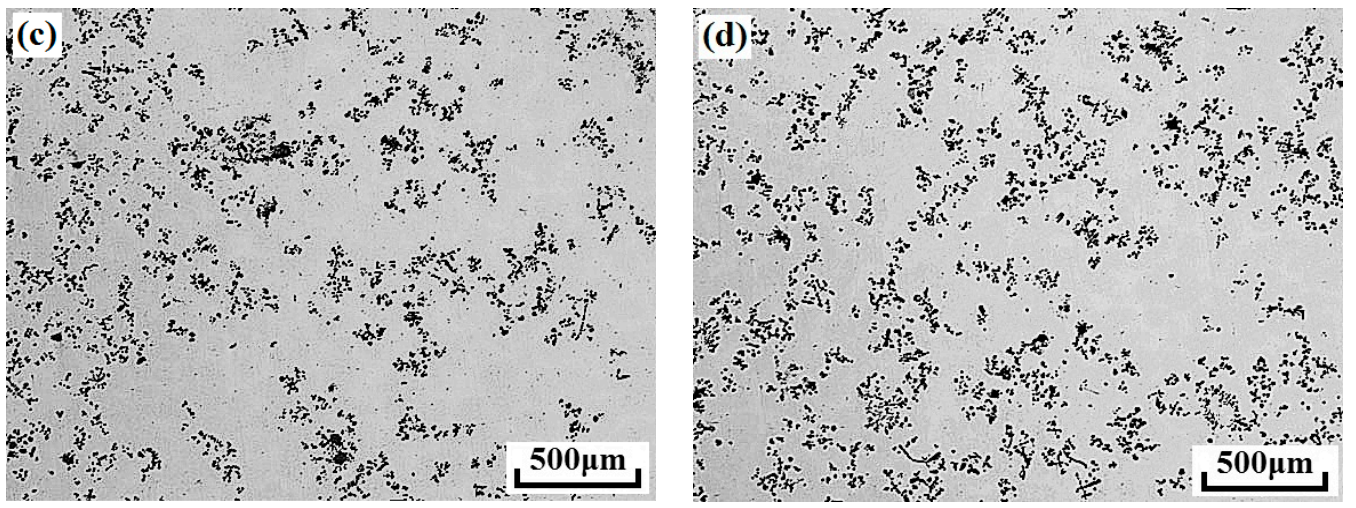

Figure 8. Microstructures of $\mathrm{Cu}-14 \mathrm{Fe}$ alloys solidified with various stirring models requires continuous stirring at the (a) edge and (b) center with alternating stirring at (c) the edge and (d) the center.

\subsection{Hole Defects}

Figure 9 presents the solidification structure of $\mathrm{Cu}-14 \mathrm{Fe}$ alloys solidified with various solidification techniques, which is defined in Table 2. We observed that gas hole defects are present in the ingots solidified under Technique I, which is shown in Figure 9a and Technique III, which is shown in Figure 9c. We observed that the ingot quality was optimized with Technique II, which is shown in Figure $9 \mathrm{~b}$. The primary Fe phases were observed to be distributed uniformly in the $\mathrm{Cu}$ matrix for the various AMF operating temperatures, but, as the temperature decreases, the dispersed Fe grains have a tendency to aggregate and the Fe grains form an obvious clustered aggregation under Technique III, which is shown in Figure 9c. Figure 10 plots the average Fe grain size for the various solidification techniques where it is clear that the Fe grains in the ingot solidified using Technique I are slightly finer than those solidified with the other techniques.
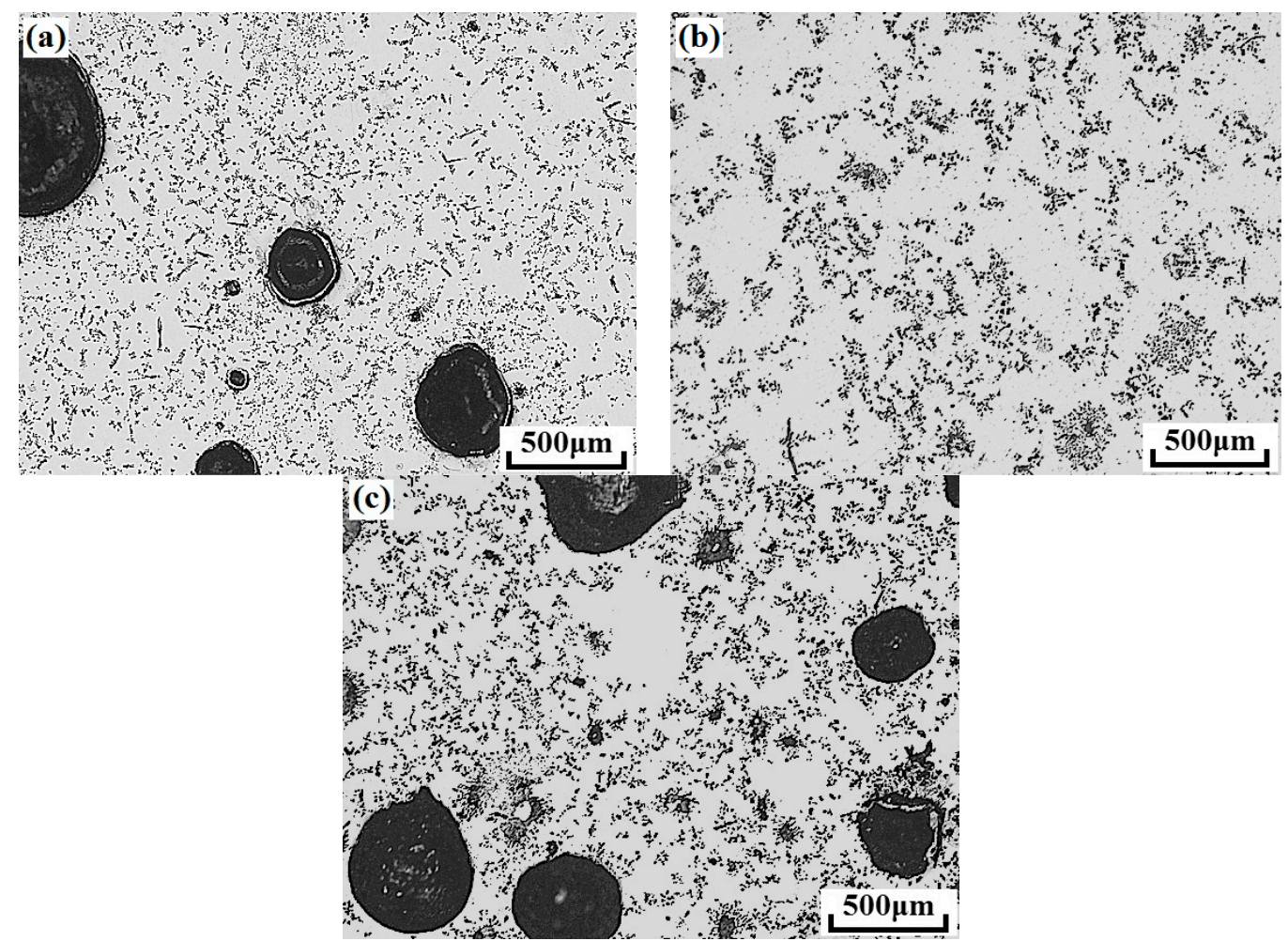

Figure 9. Microstructure of $\mathrm{Cu}-14 \mathrm{Fe}$ alloys with various solidification techniques. (a) Technique I, (b) Technique II, and (c) Technique III. 


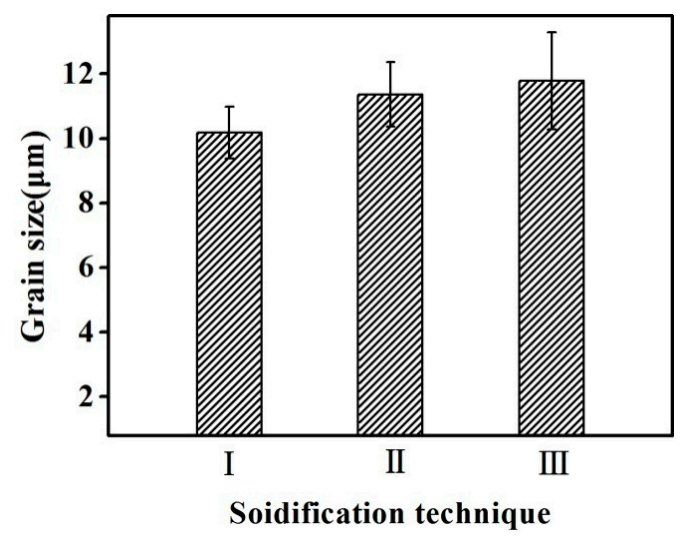

Figure 10. Average Fe grain sizes with various solidification techniques.

\section{Discussion}

\subsection{Microstructural Influence Mechanism}

The growth process of the primary Fe phase is affected by heat diffusion and solute diffusion. Furthermore, the AMF generates a Lorentz force in the melt that produces forced convection. Therefore, this reduces the temperature gradient and solute imbalance within the melt. Figure 11 plots the temperature distribution curves in the melt with and without AMF. $R$ is the distance to the melt center. Under conventional solidification, the melt temperature is highest at the center and gradually decreases as a function of distance from the center. Therefore, a relatively large temperature gradient in the melt is exhibited (e.g., the temperature in various positions at $t=300 \mathrm{~s}$ is $1157^{\circ} \mathrm{C}, 1137^{\circ} \mathrm{C}$, and $1096{ }^{\circ} \mathrm{C}$, respectively), which is shown in Figure 11a. With the application of AMF, however, the temperature gradient $\Delta T$ noticeably decreases and temperature distribution in the melt tends to be more uniform (the temperature in various positions at $t=300 \mathrm{~s}$ is $1142{ }^{\circ} \mathrm{C}, 1127^{\circ} \mathrm{C}$, and $1106{ }^{\circ} \mathrm{C}$, respectively), which is shown in Figure 11b. It is evident that the convection caused by the AMF delays the melt cooling rate at the wall and the surface and accelerates the cooling rate of the entire melt, which causes the temperature field to be more uniform in the melt.
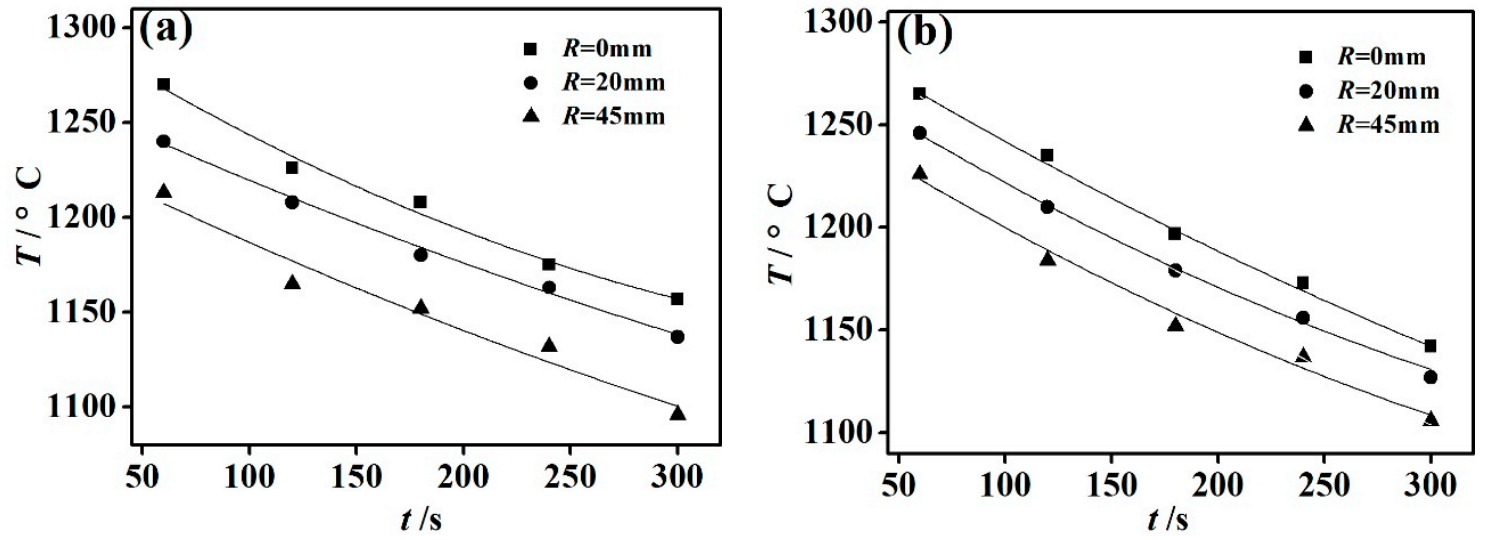

Figure 11. Temperature distribution in melt (a) without AMF and (b) with AMF.

This uniform temperature field influences the growth of the primary Fe phase from grain nucleation and growth. The influence mechanisms of AMF upon the nucleation and growth process of the grains outlined in two modes.

(1) Nucleation of detached grains. The grain usually nucleates from the crystallizer wall during the solidification process because the wall possesses the lowest temperature and can provide the 
nucleation platform. An electromagnetic force (i.e., with AMF), however, causes forced convection in the melt whose fluid flow will easily knock the crystal nucleus from the crystallizer wall to then flow into the melt. This fluid flow also decreases the temperature gradient in the melt and promotes uniformity in the melt temperature. If the detached grains cannot fully fuse, the supercooled liquid surrounding them will solidify and grow around the grain core that then plays the role of the nucleus for the formation of sphero-crystals. Moreover, the uniform temperature will prevent the formation of the surface skull on the crystallizer wall and promotes the detachment of more grains from the crystallizer wall [32].

(2) Nucleation of fusing dendrites. During the dendritic growth process, the solute concentration at the front of the dendrite is lower than the solute concentration at the interdendritic. Since a higher solute content induces a greater degree of liquid supercooling and a reduced interface growth rate, the dendrites are extruded and form "necking" dendrite arms at the root during the growth process, which forms dendrites with coarse ends and thin roots. With the application of AMF, the induced convection will flush the dendrite arms and decrease the supercooling degree at the front of the solid-liquid interface, which may cause the "necking" dendrite arms to melt again [33]. Simultaneously, dendrite arms flowing free in the melt can cause grain multiplication and promote grain refinement.

Based on these phenomena, the AMF influences the grain growth process through the variation of the temperature and solute fields, which transforms the morphology of the solidification structure. The magnitude of the magnetic flux density also has a significant influence on the grain growth where an increased magnetic flux density enhances the electromagnetic force present in the melt and produces a more intense convection therein. Therefore, the effects of the AMF on grain refinement and dispersed distribution are more significant. According to the electromagnetism theory, when a current $J$ is supplied on a metal with a resistivity $\rho$, it will generate a heat $Q$ [34].

$$
Q=J^{2} \times \rho
$$

This heat effect in the solidification system will also increase with an increased and induced current. An increased magnetic flux density will cause a growth of the induced current, which will, in turn, raise the temperature and reduce the supercooling degree in the melt. At the same time, the increased induced current may reduce the nucleation rate and grain coarsening.

Therefore, the AMF exhibits a two-fold action on the growth of the primary Fe phase. It produces a Lorentz force that causes convection, which promotes the refinement and spheroidizing of the grains. However, the heat effect may decrease the supercooling degree of the melt and increase the grain size. Convection plays a dominant role under a low magnetic flux density. However, as the magnetic flux density increases, the heat effect gradually intensifies, which will cause Fe grain coarsening. Therefore, an optimized value of magnetic flux density is needed to refine the Fe phase.

\subsection{Macrosegregation Influence Mechanism}

In this experiment, serious gravity segregation appeared in the ingot solidified without AMF with almost no primary Fe phase occurring at the bottom of the ingot and a greater volume fraction of $\mathrm{Fe}$ phase at the top of the ingot than in other positions. The reason for this gravity segregation is related to the physical properties of the $\mathrm{Cu}-\mathrm{Fe}$ alloy. When the primary Fe phase crystallizes from the melt, the solid phase acts on the floatage $\Delta G$ such that

$$
\Delta G=\left(\rho_{\mathrm{Cu}}-\rho_{\mathrm{Fe}}\right) g \times V_{\mathrm{Fe}}
$$

where $\rho_{\mathrm{Cu}}$ and $\rho_{\mathrm{Fe}}$ are the densities of the $\mathrm{Cu}$ melt and the Fe solid phase, respectively, $g$ is the acceleration of gravity, and $V_{\mathrm{Fe}}$ is the volume of the Fe grain. The melt has a relatively slow solidification rate in the preheated crystallizer because the Fe density is less than that of $\mathrm{Cu}$. The Fe solid phase has sufficient time to float up under the action of floatage. Almost none of the Fe phase is distributed at the bottom of the ingot. 
When the melt is solidified with AMF, however, the magnetic field induces electromagnetic stirring and creates a forced convection in the melt. The convection caused by rotation of the melt not only makes the temperature and solute distribution more uniform, but also the Lorentz force can produce a laminar or turbulent flow in the melt. A greater magnetic flux density has a greater influence via the Lorentz force, which can weaken the effect of floatage on the Fe solid phase in the direction of gravity and promotes uniform Fe phase distribution in the ingot.

The influence that the stirring mode has on the solidification structure is reflected in the variation of the force direction in the melt. With continuous stirring, the rotating melt is acted on by a centrifugal force where the electromagnetic resultant force $F$ applied to a solid phase with volume $v$ is given by $F_{s}=1.5 J \times B \times v$ in which $J$ is the excitation current and $B$ is the magnetic flux density. This is greater than that applied to the liquid phase at the same volume, $F_{l}=J \times B \times v$, which resulted in a flow velocity difference between the Fe phase and the $\mathrm{Cu}$ liquid [35]. As a result of this velocity difference, the primary Fe phase may transfer to the outer edge of the ingot and, as the temperature reduces and the melt gradually solidifies, a higher volume fraction of the Fe phase will be present at the outer edge of the ingot. This causes a non-uniform Fe phase distribution in the ingot.

With the alternating stirring model, the cycle of stirring $\rightarrow$ stopping $\rightarrow$ reverse stirring induces in the melt a flow cycle of accelerating $\rightarrow$ slowing down $\rightarrow$ reverse accelerating. The variation of the electromagnetic force direction produces an unstable flow in the melt and reduces the centrifugal force transfer phenomena, which promotes a uniform distribution of the Fe phase in the ingot.

\subsection{Hole Defects Influence the Mechanism}

The $\mathrm{Cu}$ alloy tends to absorb gas in the high-temperature melt process. The primary gas released from the melt in the solidification process is hydrogen. As the temperature then decreases, hydrogen is released from the melt because of the reduction of the solubility. Furthermore, the melt surface tends to form a surface skull that results in the incomplete discharge of gas and the formation of gas holes at the top of the ingot. The application of AMF causes an intense liquid flow that will continuously flush the solid phase surface, which can increase the escape velocity of the bubbles. In addition, the uniform temperature field can delay the formation of the surface skull. Therefore, the gas can be fully released from the ingot and the gas hole defects are mitigated.

If the AMF operating temperature is too high, intense convection will result in melt boiling, which causes secondary gases to be absorbed into the melt and reduces the degassing effect. In these circumstances, residual microscopic gas holes are found in the ingot after solidification. If the AMF operating temperature is too low, the melt will transform into a semi-solid because of the growth of the Fe solid phase. In addition, the increase in melt viscosity will weaken the convection effect.

Figure 12 plots the curves of the solid fraction and viscosity as a function of temperature. ProCAST has a material database and a thermodynamic database for most alloys. The thermodynamic parameters such as liquidus, solidus, specific heat, and more can be simulated with the chemical components. The solid fraction and viscosity of the $\mathrm{Cu}-14 \mathrm{Fe}$ alloy can be obtained by entering the mass fraction of copper and iron in the ProCAST software. As the temperature decreases, the volume fractions of the Fe phase increases in the melt, which is shown in Figure 12a. In particular, the melt viscosity increases by approximately $20 \%$ when the temperature drops to $1260{ }^{\circ} \mathrm{C}$, which is shown in Figure 12b. At the same time, a skull begins to form on the melt surface, which causes incomplete discharge of gas and forms gas holes in the ingot. 

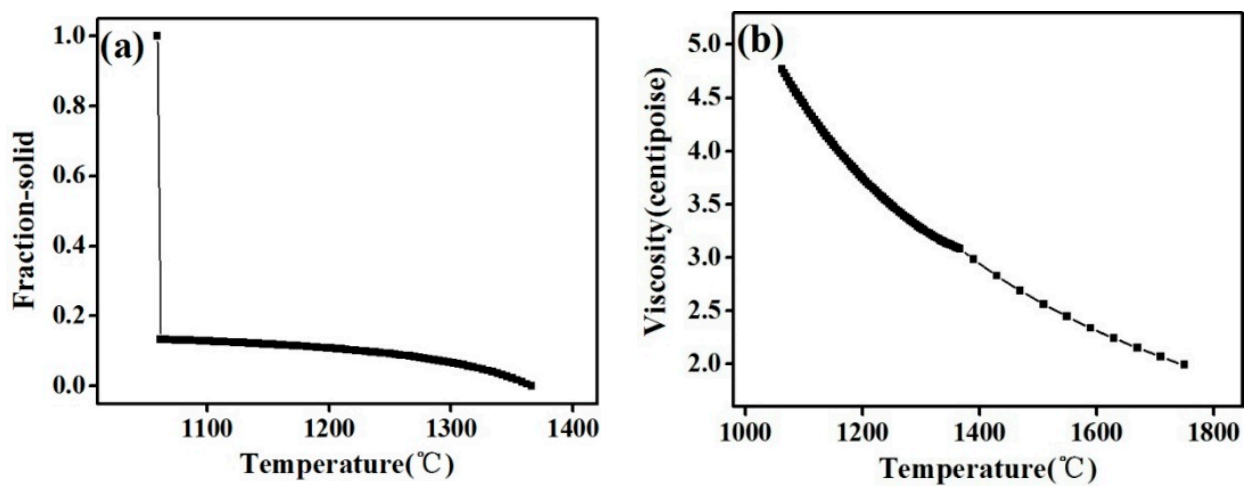

Figure 12. Calculated values of $\mathrm{Cu}-14 \mathrm{Fe}$ alloy thermophysical parameters. (a) Solid Fraction-Temperature curve and (b) Viscosity-Temperature curve.

\section{Conclusions}

In this paper, solidification behaviors of the $\mathrm{Cu}-14 \mathrm{Fe}$ alloys under an AMF were systematically discussed. The growth and distribution of the primary Fe phase were studied and the influence that the magnetic flux density, stirring model, and solidification technique has upon the solidification structure was analyzed. The conclusions are shown below.

(1) The AMF application can refine the Fe phases and promote the transformation of the Fe dendrite to rosettes or spherical grains. The AMF affects the growth process of the primary Fe phase through two aspects: the nucleation of detached grains and the nucleation of fusing dendrites.

(2) By increasing magnetic flux density, the Fe phase is further refined and distributed more uniformly. However, when the magnetic flux density exceeds a certain value, the increasing heat through induction will reduce crystal refining by forced convection, which resulted in $\mathrm{Fe}$ grain coarsening.

(3) The AMF application inhibits floating of the primary Fe phase during the solidification process and promotes uniform Fe phase distribution in the ingots. The alternating stirring mode is conducive for reducing segregation of the Fe phase because of the variation in the electromagnetic force direction. An appropriate AMF operating temperature can effectively refine the grain size and reduce gas hole defects in the ingot.

Author Contributions: Conceptualization, J.Z. Data curation, Z.Z. Funding acquisition, D.-P.L. and K.-M.L. Investigation, K.-M.L. and Q.-F.F. Methodology, D.-P.L. Writing-original draft, J.Z.

Funding: This study was funded by the National Natural Science Foundation of China (No. 51461018; 51561010), Jiangxi Academy of Sciences (No.2017-YZDZ-07).

Acknowledgments: The authors wish to thank H.X. Zheng for revising the manuscript.

Conflicts of Interest: The authors declare no conflict of interest.

\section{References}

1. Bevk, J.; Harbison, J.P.; Bell, J.L. Anomalous increase in strength of insitu formed Cu-Nb multifilamentary composites. J. Appl. Phys. 1978, 49, 6031-6038. [CrossRef]

2. Pantsyrny, V.; Shikov, A.; Khlebova, N.; Drobishev, V.; Kozlenkova, N.; Polikarpova, M.; Belyakov, N.; Kukina, O.; Dmitriev, V. The nanostructured high strength high conductivity $\mathrm{Cu}$ matrix composites with different BCC metals strengthening filaments. IEEE Trans. Appl. Supercond. 2010, 20, 1614-1618. [CrossRef]

3. Gan, C.L.; Liu, H.; Zheng, K.H.; Liu, Y.N.; Wang, H.Y. Manufactured process of high strength and high electrical conductivity Cu-Cr-Zr-Mg alloy bars. Mater. Sci. Forum 2017, 898, 1215-1219. [CrossRef]

4. Liu, K.; Lu, D.; Zhou, H.; Yang, Y.; Atrens, A.; Zou, J. Microstructure and properties of a deformation-processed $\mathrm{Cu}-\mathrm{Cr}-\mathrm{Ag}$ in situ composite by directional solidification. J. Mater. Eng. Perform. 2013, 22, 3723-3727. [CrossRef] 
5. Liu, K.; Lu, D.; Fu, K.; Luo, P.; Huang, Z.; Guo, W.; Yu, J.; Zou, J.; Hu, Q. Evolution of microstructure in a $\mathrm{Cu}-\mathrm{Cr}$ in situ composite produced by thermo-mechanical processing. J. Mater. Sci. Chem. Eng. 2017, 5, $29-35$. [CrossRef]

6. Li, Y.; Liu, R.Q.; Xu, F. Effect of Ce addition on the microstructure and properties of Cu-10Fe-3Ag in situ composite. Adv. Mater. Res. 2012, 366, 357-360. [CrossRef]

7. Liu, K.; Jiang, Z.; Zhao, J.; Zou, J.; Lu, L.; Lu, D. Thermal stability and properties of deformation-processed Cu-Fe in situ composites. Metall. Mater. Trans. A 2015, 46, 2255-2261. [CrossRef]

8. Li, Y.; Yi, D.; Zhang, J. Comparative study of the influence of ag on the microstructure and mechanical properties of Cu-10Fe in situ composites. J. Alloy. Compd. 2015, 647, 413-418. [CrossRef]

9. Matsukawa, M.; Takahashi, C.; Yamada, H.; Noto, K.; Sato, T.; Kawabe, H. High-strength high-conductivity $\mathrm{Cu}-\mathrm{Nb}$ composite wires. Teion Kogaku 2010, 25, 265-269. [CrossRef]

10. Xiaobo, M.A.; Liang, M.; Yafeng, L.U.; Chengshan, L.I.; Xiaoyan, X.U.; Wang, P. Research progress on Cu-Nb micro-composites with high strength and conductivity. Mater. Rev. 2013, 24, 2787-2790.

11. Rdzawski, Z.; Gluchowski, W.; Stobrawa, J.; Kempinski, W.; Andrzejewski, B. Microstructure and properties of nanofilament $\mathrm{Cu}-\mathrm{Nb}$ and $\mathrm{Cu}-\mathrm{Ag}$ composites. Physics 2014, 74, 689-697.

12. Sun, A.; Wu, Z.; Dong, X.; Duan, B.; Wang, D. Effects of ag addition on electrical and thermal properties of Mo-Cu composites. J. Alloy. Compd. 2016, 657, 8-11. [CrossRef]

13. Stolk, J.; Manthiram, A. Chemical synthesis and characterization of low thermal expansion-high conductivity Cu-Mo and Ag-Mo composites. Metall. Mater. Trans. A 2000, 31, 2396-2398. [CrossRef]

14. Sakai, Y.; Hibaru, T.; Miura, K.; Matsuo, A.; Kawaguchi, K.; Kindo, K. Development of high strength-high conductivity Cu-6 wt \% Ag alloy for high field magnet. Mrs Adv. 2016, 1, 1137-1148. [CrossRef]

15. Inoue, K.; Sakai, Y.; Asano, T.; Maeda, H. Cu-Ag microcomposite alloy and its applications to generate extremely high magnetic fields. Teion Kogaku 2010, 30, 163-170. [CrossRef]

16. Bao, G.H.; Chen, Y.; Ma, J.E.; Fang, Y.T.; Meng, L.; Zhao, S.M.; Wang, X.; Liu, J.B. Microstructure and properties of cold drawing $\mathrm{Cu}-2.5 \% \mathrm{Fe}-0.2 \% \mathrm{Cr}$ and $\mathrm{Cu}-6 \% \mathrm{Fe}$ alloys. J. Zhejiang Univers. Sci. A 2015, 16, 622-629. [CrossRef]

17. Slimi, M.; Azabou, M.; Escoda, L.; Suñol, J.J.; Khitouni, M. Structural and microstructural properties of nanocrystalline $\mathrm{Cu}-\mathrm{Fe}-\mathrm{Ni}$ powders produced by mechanical alloying. Powder Technol. 2014, 266, $262-267$. [CrossRef]

18. Jo, H.R.; Kim, J.T.; Hong, S.H.; Kim, Y.S.; Park, H.J.; Park, W.J.; Jin, M.P.; Kim, K.B. Effect of silicon on microstructure and mechanical properties of Cu-Fe alloys. J. Alloy. Compd. 2016, 707, 184-188. [CrossRef]

19. Shi, G.D.; Jiang, H.; Wang, Z.D.; Chen, X.H. Microstructure and properties of Cu-Fe-Co alloy obtained by directional solidification. In Electronics, Electrical Engineering and Information Science: Proceedings of the 2015 International Conference on Electronics, Electrical Engineering and Information Science (EEEIS2015), Guangzhou, China, 2016; World Scientific Publishing Company: Singapore, 2016; pp. 957-965.

20. Liu, K.; Huang, Z.; Zhang, X.; Lu, D.; Atrens, A.; Zhou, H.; Yin, Y.; Yu, J.; Guo, W. Influence of ag micro-alloying on the thermal stability and ageing characteristics of a $\mathrm{Cu}-14 \mathrm{Fe}$ in-situ composite. Mater. Sci. Eng. A 2016, 673, 1-7. [CrossRef]

21. Zhao, Z.; Cui, J.; Dong, J.; Wang, Z.; Zhang, B. Effect of low-frequency magnetic field on microstructures of horizontal direct chill casting 2024 aluminum alloy. J. Alloy. Compd. 2005, 396, 164-168. [CrossRef]

22. Zuo, Y.; Cui, J.; Dong, J.; Yu, F. Effect of low frequency electromagnetic field on the constituents of a new super high strength aluminum alloy. J. Alloy. Compd. 2005, 402, 149-155. [CrossRef]

23. Steinbach, S.; Ratke, L. The effect of rotating magnetic fields on the microstructure of directionally solidified Al-Si-Mg alloys. Mater. Sci. Eng. A 2005, 413-414, 200-204. [CrossRef]

24. Vives, C. Electromagnetic refining of aluminum alloys by the crem process: Part I. Working principle and metallurgical results. Metall. Mater. Trans. B 1989, 20, 623-629. [CrossRef]

25. Vives, C. Electromagnetic refining of aluminum alloys by the crem process: Part II. Specific practical problems and their solutions. Metall. Mater. Trans. B 1989, 20, 631-643. [CrossRef]

26. Chen, Z.; Chen, X.; Li, J.; Wen, S. Effect of frequency and intensity of rotating magnetic field on the microstructures of Pb-Sn alloys. Chin. Sci. Bull. 2008, 53, 2575-2581. [CrossRef]

27. Cao, Z.; Jia, F.; Zhang, X.; Hao, H.; Jin, J. Microstructures and mechanical characteristics of electromagnetic casting and direct-chill casting 2024 aluminum alloys. Mater. Sci. Eng. A 2002, 327, 133-137. 
28. Zhao, Z.; Cui, J.; Dong, J.; Zhang, B. Effect of low-frequency magnetic field on microstructures and macrosegregation of horizontal direct chill casting 7075 aluminum alloy. J. Mater. Process. Technol. 2007, 182, 185-190. [CrossRef]

29. Jerman, G.A.; Anderson, I.E.; Verhoeven, J.D. Strength and electrical conductivity of deformation-processed Cu-15 vol PctFe alloys produced by powder metallurgy techniques. Metall. Trans. A 1993, $24,35-42$. [CrossRef]

30. Kumar, N.V.R.; Blandin, J.J.; Desrayaud, C.; Montheillet, F.; Suéry, M. Grain refinement in AZ91 magnesium alloy during thermomechanical processing. Mater. Sci. Eng. A 2003, 359, 150-157. [CrossRef]

31. Bowen, J.R.; Gholinia, A. Analysis of the billet deformation behaviour in equal channel angular extrusion. Mater. Sci. Eng. A 2000, 287, 87-99. [CrossRef]

32. Vivès, C. Solidification of tin in the presence of electric and magnetic fields. J. Cryst. Growth 1986, 76, 170-184. [CrossRef]

33. Cadırlı, E.; Kaya, H.; Räbiger, D.; Eckert, S.; Gündüz, M. Effect of rotating magnetic field on the microstructures and physical properties of Al-Cu-Co ternary eutectic alloy. J. Alloy. Compd. 2015, 647, 471-480. [CrossRef]

34. Yu, Y.D.; Li, C.X. The effect of alternative low frequency electromagnetic field on the solidification microstructure and mechanical properties of ZK60 alloys. Mater. Des. 2013, 44, 17-22. [CrossRef]

35. Vivès, C. Elaboration of metal matrix composites from thixotropic alloy slurries using a new magnetohydrodynamic caster. Metall. Trans. B 1993, 24, 493-510. [CrossRef]

(C) 2018 by the authors. Licensee MDPI, Basel, Switzerland. This article is an open access article distributed under the terms and conditions of the Creative Commons Attribution (CC BY) license (http://creativecommons.org/licenses/by/4.0/). 